\title{
FUNDOS DE PENSÃO, CAPITAL ESTATAL E NEODESENVOLVIMENTISMO
}

\author{
José Menezes Gomes
}

Universidade Federal de Alagoas (UFAL)

\section{FUNDOS DE PENSÃO, CAPITAL ESTATAL E NEODESENVOLVIMENTISMO}

Resumo: $O$ artigo analisa os limites da concepção de desenvolvimento econômico decorrente da mudança do cenário internacional, desde 2003, com a alteração do fluxo internacional de capitais para os países subdesenvolvidos, acompanhado da expansão chinesa e valorização das commodities. Destaca o papel atribuído aos fundos de pensão pelo governo Lula da Silva para justificar a Contrarreforma da Previdência. Aborda o papel do BNDES e o subsídio ao grande capital. Demarca a queda da taxa básica nos EUA e seus impactos sobre a economia brasileira. Argumenta que o pagamento de juros e amortização da dívida pública se converteu no mecanismo através do qual o Estado retira recursos dos trabalhadores, através de impostos diretos e indiretos e os remete aos banqueiros e fundos de pensão. Enfatiza a generalização do neoliberalismo, visando resolver a crise capitalista através da renegociação da dívida externa, das aberturas comercial e financeira, das privatizações.

Palavras-chave: Fluxo internacional de capitais, fundos de pensão, neoliberalismo, dívida pública.

\section{PENSION FUNDS, STATE-OWNED CAPITAL AND NEO-DEVELOPMENTISM}

Abstract: The article analyzes the limits of conception of economic development arising from the change of the international scenery, since 2003, with the alteration of the international flux of capitals to the sub-developed countries, accompanied of chinese expansion and commodities' appreciation. It highlights the assigned role to the pension funds by Lula da Silva's government to justify the counter-reform of the Provident Funds. It approaches the role of BNDES and the subsidy to the grand capital. Demarcates the fall of the basic tax in the USA and its impacts on the Brazilian economy. Argues that the payment of taxes and the amortization of the public debt was converted in the mechanism through which the State withdraw resources from workers, through the direct and indirect taxes and refer those to the bankers and pension funds. Emphasizes the generalization of neoliberalism, seeking to resolve the capitalist crisis through the renegotiation of external debt, of the commercial and financial openings, and of privatizations.

Keywords: International flux of capitals, pension funds, neoliberalism, public debt. 


\section{INTRODUÇÃO}

O presente texto visa analisar os limites da concepção de desenvolvimento econômico que resultou da mudança de cenário internacional, desde 2003, com a mudança do fluxo internacional de capitais para os países subdesenvolvidos, acompanhado pela expansão chinesa e valorização das commodities. Nesse âmbito, destaca-se o papel atribuído aos fundos de pensão pelo governo Lula da Silva para justificar a Contrarreforma da Previdência do referido ano, como gerador de poupança de longo prazo e garantidor do investimento privado. Tal visão encobre que esses fundos são, na essência, responsáveis pela rolagem de parte da própria dívida pública e ao mesmo tempo se beneficiam do crédito estatal subsidiado.

Nessa direção, inicialmente fazemos um resgate da crise de 2008, sua severidade e os dispêndios com a nova etapa de dívida pública. Em segundo lugar, abordamos o papel do BNDES e o subsídio ao grande capital. Em terceiro lugar, investigamos a queda da taxa básica nos EUA e seus impactos sobre a economia brasileira, seja na taxa de investimento como no rendimento dos fundos de pensão e o sacrifício que o governo faz ao transferir recursos do Tesouro nacional vindos do corte de despesas sociais.

Nesse cenário, o pagamento de juros e amortização da dívida pública se converteu no mecanismo por onde o Estado retira recursos dos trabalhadores, através dos impostos diretos e indiretos e os remete diretamente aos banqueiros e fundos de pensão. Esse processo resultou da crise fiscal e financeira do Estado, a partir dos anos 70, e a explosão da dívida pública, que estabeleceu uma nova relação entre Estado, bancos e economia. O ponto culminante desse fenômeno foi a generalização do neoliberalismo, visando resolver a crise capitalista através da renegociação da dívida externa, das aberturas comercial e financeira, das privatizações.

\section{CRISE CAPITALISTA DE 2008 E SUA PERSISTÊNCIA}

A crise capitalista explicitada em 2008 revelou a cortina de fumaça do chamado modelo neoliberal, enquanto soma gigantesca de US\$ 16 trilhões ${ }^{1}$ foi liberada na forma de empréstimos pelo FED - Banco Central dos EUA aos grandes bancos e indústrias. Se durante muito tempo foi divulgado que os estados nacionais não tinham dinheiro para bancar as ditas funções sociais, de repente lançaram mão de recursos públicos especialmente para salvar os bancos e os demais rentistas. Ao mesmo tempo, estes estados continuaram a pagar o serviço da dívida pública. A crise e seus efeitos criaram um novo gigantesco endividamento para os contribuintes.

Segundo estudo do Instituto Assaf, entre 2008 e 2011 a crise econômica mundial deixou perdas gigantescas de US\$ 50,4 trilhões nas bolsas mundiais. Em média, o valor destas perdas em dezembro de 2011 ficou 12\% inferior em relação a 2007. Se compararmos os valores de mercado de 2007 com os valores de 2011, os EUA apresentaram queda significativa de 53\%; a Europa, perda de 42\%. A Austrália, Nova Zelândia e Canadá tiveram alta de $3 \%$; o Japão, de $9 \%$ e os mercados emergentes, de $22,6 \%$. Apesar de não representarem numericamente a maioria das bolsas, os mercados americanos e europeus puxam para baixo a média mundial, já que possuem a maior parte do volume financeiro movimentado. Nesse mesmo período, no Brasil, a Bovespa desvalorizou-se US\$ 175,6 bilhões ou $12,55 \% .^{2}$

A crise de 2008 trouxe novos determinantes não só por sua intensidade como pela dosagem do remédio adotado pelos países centrais: massiva estatização de bancos e grandes empresas industriais como pela gigantesca emissão monetária e queda das taxas básicas de juros próximas de zero nos países que representam mais de $80 \%$ do PIB mundial, provocando uma nova onda de liquidez mundial.

\section{O PAPEL DO BNDES E O SUBSÍDIO AO GRANDE CAPITAL}

$\mathrm{Na}$ tentativa de conter os efeitos da crise capitalista mundial de 2008, o governo brasileiro interveio no sentido de resguardar os interesses privados, pois além de salvar bancos e grandes empresas, lançou mão do dinheiro público para impulsionar os gastos com as obras da Copa de 2014, as grandes hidrelétricas e olimpíada de 2016. Ao mesmo tempo, aumentava o volume de recursos subsidiados emprestados pelo BNDES para essa finalidade. Parte desses recursos vinha dos créditos do Tesouro Nacional acompanhados pelos sucessivos cortes no Orçamento da União das chamadas despesas sociais. Segundo a própria presidente, o corte de $\mathrm{R} \$ 50$ bilhões, em 2011, não iria recair sobre os investimentos do Programa de Aceleração do Crescimento - PAC, nem nos gastos com a copa de 2014, prioritários para os lucros das empreiteiras. O motivo do corte continuou a ser o mesmo: pagar a dívida pública e assegurar os ganhos dos bancos e dos fundos de pensão. Parte dessa dívida foi contraída como fruto dos efeitos da crise capitalista mundial, em especial os recursos usados desde 2008 para salvar bancos, empreiteiras, montadoras, agronegócio. Isso não ocorre por acaso, já que as empreiteiras tiveram um papel decisivo nas últimas eleições. 
Parte dos recursos do BNDES serviu para impulsionar a política de formação de grandes empresas brasileiras através do auxilio a fusão e aquisição de grupos considerados estratégicos pelo governo para a disputa de mercado no exterior. Ou seja, fortalecer a expansão de setores monopolistas ditos nacionais com dinheiro subsidiado. Teve destaque também a liberação de recursos para o financiamento de empresas interessadas no processo de privatização de aeroportos, portos, rodovias, ferrovias. Isso ficou claro em 2011, quando o BNDES emprestou R\$ 140 bilhões, sendo 40\% para infraestrutura, a partir de repasses do Tesouro Nacional. Todavia, parte dos recursos foi destinada a estímulo da nova etapa de privatização de aeroportos e rodovias federais. O crédito barato do BNDES para até $80 \%$ dos investimentos nos terminais foi um fator decisivo nas contas dos consórcios que resultaram num ágio médio de $347 \%$ e arrecadação de $\mathrm{R} \$$ 24,7 bilhões. Ou seja, a iniciativa é privada, mas o banco é estatal e quem paga a conta final é a classe trabalhadora, que ficará sem serviço público, pois parte dos recursos usados por esse banco estatal vem de repasses oriundos do Tesouro, mediante cortes ocorridos nos investimentos sociais.

Dessa forma, os fundos de pensão vivem nos vários momentos, juntamente com os grandes capitalistas no uso de dinheiro público em várias etapas, seja no momento da linha de crédito subsidiado para comprar empresas estatais ou privadas, seja na obtenção de renúncias fiscais como proprietários de parte destas grandes empresas, dentro da chamada politica industrial, e principalmente na apropriação de grande parte da receita pública na forma de pagamento do serviço da dívida pública, já que são grandes compradores da dívida pública. Com isso, eles assumem uma dupla e conflitante função: na primeira seriam as molas propulsoras do desenvolvimento capitalista, como acionistas e gestores de grandes empresas, associados com as grandes empreiteiras. Do outro lado, esses fundos são decisivos na rolagem da dívida pública, já que grande parte dos recursos dos fundos está envolvida na rolagem da dívida.

No primeiro momento recebem empréstimos com juros subsidiados do BNDES de $5 \%$ ao ano. Em seguida emprestam dinheiro ao próprio Estado a $12 \%$ ao ano através da compra de títulos públicos. Para bancar o BNDES nesta tarefa suicida, o Tesouro Nacional libera recursos que acabam por ampliar ainda mais a dívida. $O$ corte nos gastos com serviços públicos acaba sendo o mecanismo para obter recursos para bancar esta nova dívida. Com a precarização do serviço vindo do baixo investimento, nesta finalidade aparece a desculpa para a privatização dos serviços ainda existentes, onde o BNDES entrará novamente financiando a juros subsidiados.

Visando aquecer a economia, a União autorizou o aumento das dívidas de 17 Estados, para que estes estados pudessem acelerar suas próprias obras de infraestrutura para estimular o crescimento econômico do país. O montante de endividamento autorizado é da ordem de $R \$ 42$ bilhões. Até então tínhamos uma proibição de novas dívidas e um rígido controle pela Lei de Responsabilidade Fiscal para assegurar o pagamento da dívida pública dos Estados e município, que fora federalizada em 1997, a taxa de juros extorsiva. Dentre os estados autorizados para mais endividamento temos, inicialmente, aqueles envolvidos com gastos para a copa de 2014.

Para bancar essa burguesia parasitária associada com os fundos de pensão, o BNDES emprestou $391 \%$ em dólares em cinco anos (2005 e 2010), enquanto os empréstimos do Bando Mundial avançaram $196 \%$, representando três vezes mais do que fez esta instituição multilateral. Somente em 2010 este banco brasileiro emprestou US\$ 96,32 bilhões, enquanto o BIRD concedeu US\$28,85 bilhões em empréstimos ${ }^{3}$.

\section{A QUEDA DA TAXA BÁSICA E O BAIXO INVESTIMENTO}

É importante lembrar que a taxa básica dos países que possuem $80 \%$ do PIB mundial no momento está próxima de zero, nos EUA, Japão, União europeia. Antes disso é importante destacar que no início dos anos 80 , na chamada política econômica de Reagan, tivemos a política dos juros altos como forma de conter os efeitos da recessão de 1980 - 81. Ou seja, o início do neoliberalismo nos EUA foi marcado pela política dos juros altos. Tal política possibilitou a estabilização do dólar e transformou os títulos do Tesouro estadunidense no objeto de desejo dos principais rentistas. Essa crescente valorização desses títulos, somada à desregulamentação financeira, à securitização das dívidas, acabaram por dar vasão à expansão dos fundos de pensão, quando se inaugura a chamada década perdida. Temos o surgimento de um novo seguimento de rentistas com um volume de recurso bem mais elevado que os bancos, com o objetivo de obtenção de previdência privada. Ou seja, quando se inaugura a década perdida explode a valorização das bolsas, enquanto se manifesta a crise de crédito. Naquele momento, os recursos dos fundos de pensão se dirigiram para o mercado de ações e para os títulos públicos, impulsionando o caráter especulativo destes mercados. $\mathrm{O}$ aumento do capital em ações não resultou em aumento da atividade econômica, na chamada década perdida. A desregulamentação financeira vai acelerar ainda mais esse processo.

A baixa da taxa de juros teve início em 1991 nos EUA, visando combater a recessão daquele período. 
Porém, em 2003 esta taxa chega a 1\% ao ano nos EUA. Todavia, desde 2008 aquele país pratica uma taxa de $0,25 \%$ ao ano, juros negativos. Os países desenvolvidos estão praticando taxas próximas de zero já faz tempo e suas respectivas economias não estão reagindo. Ao contrário, cada etapa de queda da taxa de juros foi acompanhada pela expansão do crédito. Todavia, cada etapa desta fez a crise de superprodução ainda mais aguda. Para conter a recessão de 1991, baixaram a taxa de juros para $6 \%$ ao ano que resultou na crise das bolsas de 2000 - 2002, onde foram perdidos US\$ 15 trilhões. Este processo ficou conhecido como a crise da economia ponto com ou da bolha da internet. A resposta aos efeitos dessa crise foi a brusca queda desta taxa para $1 \%$ ao ano, em 2003, feita pelo Banco Central dos EUA. Este fator somado à expansão da economia chinesa e indiana, mais a grande valorização das commodities, possibilitaram às economias subdesenvolvidas uma expansão. Todavia, esta expansão foi marcada por um processo de desindustrialização e de re-primarização na economia brasileira.

O Estado brasileiro, que, de várias formas, possibilitou a expansão nos anos 70, acabou se exaurindo como motor do desenvolvimento, tornandose refém desses mesmos agentes privados, para poder rolar sua dívida nos anos 90 . Isso porque, já estava endividado em 1994, no início do Plano Real, ficou ainda mais em 2011, comprometendo ainda mais a capacidade de financiamento do Estado nas funções anticíclicas, além de abandonar quase que inteiramente a chamada função social.

O deslocamento de recursos, especialmente para os países subdesenvolvidos, contribuiu para uma nova onda de valorização das bolsas, especialmente a bolsa brasileira. Essa mudança brusca de cenário internacional vai ser decisiva no mandato do presidente Lula da Silva até 2008. Se no período de 1994 a 2002 o cenário internacional foi marcado por seguidas etapas da crise de superprodução manifestada em países subdesenvolvidos como a crise mexicana em 1995, crise asiática em 1997, crise russa em 1998, crise argentina em 2001, a partir dai a crise vai se manifestar no epicentro do capitalismo, especialmente nos EUA.

Se antes tínhamos crescentes fugas de capitais contidas por elevações persistentes da taxa básica de juros no Brasil, a partir da crise de 2000 2002 e das iniciativas de contenção dos seus efeitos recessivos, o que tivemos foi um deslocamento de capitais dos países centrais para os países subdesenvolvidos. Esta gigantesca expansão da liquidez mundial, ao contrário de conter a crise anterior, a fez ainda mais amplificada levando à crise de 2008, onde as perdas nas bolsas chegaram a mais de US\$ 40 trilhões, especialmente nos EUAe Europa, Japão e China.

Dentro do chamado neodesenvolvimentismo o Programa de Aceleração do Crescimento - PAC foi colocado como instrumento de contenção dos efeitos da crise capitalista mundial de 2008. Todavia, o PAC buscava retomar o conjunto de iniciativas propostas pelo Programa Avança Brasil do governo FHC. O Plano Plurianual PPA, conhecido como o programa Avança Brasil, foi desenvolvido para o segundo mandato de Fernando Henrique Cardoso (1998 - 2002), visando à continuidade de seu projeto anterior, o programa Brasil em Ação. Este programa foi criado por José Paulo Silveira, inspirado em um texto de Eliezer Batista, pai de Eike Batista 4 .

Segundo Oliveira e Ponte (2006, p 1), o crescimento dos fundos de pensão no Brasil

[...] vem sendo incentivado pelo governo federal, na tentativa de ampliar a poupança nacional, estável e de longo prazo, de modo a diminuir a dependência da nossa economia do capital estrangeiro.

Dessa forma, tenta-se superar a vulnerabilidade externa marcante das fases anteriores. Esse argumento está presente na exposição de motivos para a reforma da previdência e criação do FUNPRESP. Dentro desse processo esperava-se que ocorresse uma expansão do mercado de capitais e, por sua vez, aumento do nível de investimento produtivo que resultasse em crescimento econômico.

Esse argumento repete as bases do colocado por Martin Wolf, colunista do jornal Financial Times, que afirmou que o principal desafio para o Brasil se tornar um país desenvolvido é aumentar o nível de poupança interna. Um dos caminhos para conseguir isso, seria o estabelecimento de um esquema nacional de poupança para pensões. ${ }^{5}$. O papel desenvolvimentista do estado brasileiro só é possível quando ele supera negativamente o parasitismo privado convertendo capital inativo em capital produtivo por sua conta e risco (XAVIER, 1995). Na essência o Estado estatiza o crédito, o consumo e parte da produção, assumindo como ônus uma nova etapa da dívida pública.

\section{CONCLUSÃO}

O papel dos fundos de pensão é mistificado, pois procura destacar uma suposta dimensão desenvolvimentista encobrindo o fato de que são responsáveis pela rolagem de uma grande parte da dívida pública e ao mesmo tempo são beneficiados por grande volume de capital estatal subsidiado via BNDES. O que temos agora é a diferenciação da manifestação de um mesmo fenômeno em tempos distintos de ocorrência, mas com resultados previstos. Na prática, o que observamos é o aprofundar de uma crise fiscal e financeira do Estado capitalista movido pela crescente desintegração da moeda fiduciária, peça fundamental da intervenção estatal desde a grande depressão dos anos 30. A 
intervenção estatal é cada vez mais elevada no sentido de resguardar os interesses daqueles que vivem de rendas, sejam os capitalistas, diretamente, como os fundos de pensão, indiretamente. Porém, os resultados quanto à retomada da taxa de investimento produtivo são cada vez mais pífios, enquanto aprofunda a crise da política monetária como instrumento da ação anticíclica do Estado. O neoliberalismo entra em crise e o que vem pela frente é mais neoliberalismo. Nos países centrais já baixaram próximos de zero e aquelas economias não dão sinais de retomada. Parte das causas da crise de superprodução que ora vivenciamos na economia mundial se deve às tentativas anteriores em contenção desta crise.

Os fundos privados para garantirem 0 futuro de alguns, ameaçam o presente e o futuro de toda a classe trabalhadora, pois quebram a solidariedade de classe e entre gerações e colocam a nossa velhice na dependência da volatilidade dos mercados especulativos. Pela anulação da Reforma da Previdência e resgate do Sistema de Seguridade Social. A defesa da Seguridade Social, entretanto, não é apenas dos trabalhadores brasileiros, mas de todos os trabalhadores do mundo.

\section{REFERÊNCIAS}

LUCE, Mathias Seibel. Brasil: nova classe média ou novas formas de superexploração da classe trabalhadora? Trabalho, Educação e Saúde, Rio de Janeiro, v. 11 n. 1, p. 169-190, jan./abr. 2013. Disponível em: <http://www.revista.epsjv.fiocruz.br/ upload/revistas/r472.pdf>. Acesso em: 16 jan. 2003.

MARX, Karl. O Capital. São Paulo: DIFEL, 1987. Livro III, v. 4 e 5.

OLIVEIRA, Lilian; PONTE, Vera Maria. O papel da controladoria nos fundos de pensão. Disponível em:<http://www.rcc.ufsc.br/edicao5/artigos_ed5/ Jan_Jun_2006_artigo5.pdf>. Acesso em: 14 out. $201 \overline{2}$.

SAMPAIO Jr, Plínio Arruda. Desenvolvimentismo e neo desenvolvimentismo: tragédia e farsa. Serviço Social e Sociedade, São Paulo, n. 112, oct../dec. 2012. Disponível em: <http://www.scielo.br/scielo. php?pid=S0101-66282012000400004\&script=sci arttext>. Acesso em: 10 jan. 2013.

TOPIK, Steven. Capital estrangeiro e o estado no sistema bancário brasileiro: 1889-1930. Revista Brasileira de Mercado de Capitais, Rio de Janeiro, v. 5 , n. 15, p. 395-421, set./dez. 1979.

XAVIER, Jurandir. A industrialização subdesenvolvida: capital, classe e Estado na industrialização brasileira. João Pessoa: Ed. UFPB, 1995.

\section{NOTAS}

1 Disponível em: <http://www.correiocidadania.com.br/ index.php?option $=$ com_content $\&$ view $=$ article\&id $=61$ 27 : manchete $030811 \&$ catid $=31$ : mundo\& Itemid $=59>$. Acesso em: 12 de jan 2013

2 Disponível em: <http://economia.estadao.com.br/ noticias/economia\%20brasil,bolsas-no-mundo-todoperdem-us-50-tri-em-quatro-anos-de-crise, 104131,0. htm>. Acesso em: 10 de nov 2012.

3 Disponível em: <http://www.estadao.com.br/noticias/ impresso,bndes-empresta-391-mais-em-5-anos-esupera-em-tres-vezes-o-banco-mundial,689817,0. htm>. Acesso em: 10 de nov 2012.

4 Disponível em: <http://bresserpereira.org.br/ver_ file_3.asp?id=1381>. Acesso em: 12 de jan 2013.

5 Disponível em: <http://www.bbc.co.uk/portuguese/ noticias/2010/09/100924_desenvolvimento_martin_ wolf_rw.shtml>. Acesso em: 10 de out 2012.

\section{José Menezes Gomes}

Economista

Doutor em História Econômica pela Universidade de São Paulo (USP)

Professor da Universidade Federal Alagoas (UFAL)

E-mail:menezesgomes1@gmail.com

Universidade Federal Alagoas - UFAL

Av. Lourival Melo Mota, s/n,

Cidade Universitária - Maceió - AL.

CEP:57072-900 